\title{
Influence of Cutting Conditions on Profile Milling of INCONEL 738LC Alloy
}

Jan Tomíček, Alexey Molotovnik

Department of machining, process planning and metrology, Faculty of mechanical engineering, CTU in Prague. Technicka 4, 16607 Praha 6 Dejvice. Czech Republic. E-mail: jan.tomicek@fs.cvut.cz

This article presents particular results from a long term research focused on machining of INCONEL alloys. As a representative of this group of material INCONEL 738LC is selected and the article presents results of different experiments conducted. The behavior of material under different conditions was evaluated with focus to define cutting condition that can be recommended as suitable cutting conditions for profile milling of material. Basic problems of profile milling are exposed with focus to the respective material. Several machining experiments are explained and archived results are discussed. Effect of tool geometry and geometrical constraints and relations during profile milling is defined. Tool wear and cutting forces were measured and evaluated. The final conclusion is a recommendation for successful machining of given material.

Keywords: Inconel 738LC, profile milling, CAM, cutting force, tool wear

\section{Acknowledgement}

This experiment was conducted under the scientific research included in the project TA02011031 - Surface integrity after application of new progressive technologies for milling on 4 and 5 axis machining centers.

\section{References}

[1] MALÝ, J. (2006). Obráběni težkoobrobitelných materiálů se zaměrením na trvanlivost břitu nástroje a velikost sil při obrábění, České vysoké učení technické v Praze, fakulta strojní, VÝZKUMNÉ CENTRUM PRO STROJÍRENSKOU VÝROBNÍ TECHNIKU A TECHNOLOGII, Praha.

[2] AUTHORS COLLECTIVE, (2012). Hodnoceni metalografických vzorkì, [Online]. Available: http://ime.fme.vutbr.cz/files/Studijni\%20opory/PHMV/ni_i738.php. [Accessed 0111 2012].

[3] ALL METALS \& FORGE GROUP, (2012). Alloy Information Report for Inconel TM 738, [Online]. Available: http://www.steelforge.com/forgings/alloys/inconel738report.php.

[4] AUTHORS COLLECTIVE, (2012). Nickel development institute - Machining Nickel Alloys handbook, [Online]. Available: $\quad$ http://www.nickelinstitute.org/ /Media/Files/TechnicalLiterature/MachiningNickelAlloys_11008_.pdf. [Accessed 0507 2012].

[5] UHLÁ̌̌, V. (2008). Problematika prvniho záběru břitu nástroje při frézování (doctoral thesis), VŠB-TUO, Fakulta strojní, Ostrava

[6] ALAUDDIN, M., MAZID, M.A.,EL BARADI, M.A., HASHMI, M.S.J. (1998) Cutting Forces In The End Milling Of Inconel 718, Journal of Materials Processing Technology, vol. 77, pp 153-159, Elsevier,

[7] GUHRING at al. (2012) Guhring / Tool catalogue 2012 [Online]. Available: http://www.guehring.cz/data/produkty/cz_64.pdf. [Accessed 1509 2014].

[8] VYSKOČIL, Z. (2013) Odborná zpráva o postupu prací a dosažených výsledích za rok 2012 projektu Výzkum integrity povrchu pro zavedení nových progresivních technologií výroby na 4- a 5-ti osých obráběcích centrech, PBS Velká bíteš, Velká Bíteš.

[9] VRABEC, M., TOMÍČEK, J. (2007). Surface Quality after 5-Axis Milling, In: Funkčné povrchy v strojárstve 2007, pp. 187-192, ISSN 1336-9199. ISBN 978-80-8075-217-0, Trenčianska univerzita, Fakulta špeciálnej techniky, Trenčín.

[10]KYNCL, J., BERÁNEK, L., KOLAŘÍK, K., PALA, Z. (2014). The Research of the Surface Profile after Profiling of Inconel 738LC, Procedia Engineering, vol. 2014, no. 69, pp. 974-979, ISSN 1877-7058

[11]KOLAŘÍK, K., PALA, Z., ČAPEK, J., BERÁNEK, L. VYSKOČIL, Z. (2014). Non-Destructive Inspection of Surface Integrity in Milled Turbine Blades of Inconel 738LC, In: Applied Mechanics and Materials, pp. 9-15, ISSN 1660-9336. ISBN 978-3-03785-977-3, Trans Tech Publications, Uetikon-Zurich

[12] GANEV, N., KOLǍ̌ÍK, K., BERÁNEK, L., MIKEŠ, P. (2014). X-Ray Diffraction Analysis Of Residual Stersses After Milling Of Super-Alloys, in: International Conference on Technics, Technologies and Education ICTTE 2014, Faculty of Technics and Technologies, Trakia University, 2014, p. 49-54. ISSN 1314-9474, Yambol. 